\title{
ON THE LIFE CYCLE AND NATURAL HISTORY OF HYMENITIS NERO (LEPIDOPTERA: ITHOMIINAE) IN COSTA RICA*
}

\author{
By Allen M. Young \\ Department of Biology, Lawrence University \\ Appleton, Wisconsin 549I I
}

A knowledge of life cycle and natural history are often important prerequisites to studies of population biology in butterflies. Although studies on the systematics and broad distribution patterns of that familiar New World Tropical group, the Ithomiinae, have been conducted (Seitz, 1924; Fox, 1956; Fox, 1968), a lot remains to be known about the biology of many species in Central America. This is surprising in light of the considerable interest in these butterflies as members of mimicry complexes. In this spirit, this paper summarizes life cycle and natural history data on a clear wing ithomiine Hymenitis nero (Hewitson) (Nymphalidae: Ithomiinae) in Costa Rica. Similar studies of several other sympatric ithomiines have either been completed (Young, in prep.) or begun, as a preliminary step towards understanding the local patterns of diversity of this family in selected tropical plant communities.

\section{MeTHODS}

Field observations were conducted during July and August 1971, and again during August 1972 at Cuesta Angel, a montane tropical wet forest locality ( $1000 \mathrm{~m}$. elev.) on the Caribbean slope of the central Cordillera in the Heredia Province of Costa Rica. Here, the study site was at the bottom of a steep ravine (about $250 \mathrm{~m}$. in depth) along the headwaters of the Rio Sarapiqui. Observations were confined to a small $(20 \times 25 \mathrm{~m})$ second-growth clearing near heavily-shaded primary-growth forest canopy.

Field studies consisted of: (I) observations of oviposition sequences, (2) records of the larval host plant, (3) notes on larval behavior, and (4) notes on adult behavior and occurrence with other ithomiids.

Laboratory studies dealt with the estimation of developmental time and description of the life cycle. For these studies, eggs, collected immediately after oviposition in the field, were brought into the laboratory (San Jose, Costa Rica) and rearing studies were done in large clear plastic bags containing ample sprigs of host plant.

*Manuscript received by the editor October 5, 1972 
Laboratory temperatures varied from 20 to $23^{\circ} \mathrm{C}$ and the average humidity was about $55 \%$.

\section{RESULTS}

The results of studies on $H$. nero are summarized under these headings: ( I) habitat and larval food plant, (2) life cycle and developmental time, (3) larval behavior, and (4) adult behavior.

Habitat and larval host plant

The butterfly is associated with the herbaceous layer of the lower understory in the primary-growth forest in the ravine where it cooccurs with various other ithomiines. (Fig. I-A). Adults of these species feed on various flowers, and particularly various Compositae (Fig. I-B) which are common at the study site. Despite the fact that several other species of ithomiids breed here, only $H$. nero oviposits and completes development on Cestrum standleyi Morton (Solanaceae), which occurs as an herbaceous member (Fig. I-C) of the lower understory. Within the confines of the study site, this plant grows as single individuals in a highly dispersed distribution. The several species of ithomiids (Fg. I-D) which breed in the same study site include: Hymenitis andromica lyra Haensch, H. nero, Pseudoscada utilla pusio (Druce), Dircenna relata Butler \& Druce, Oleria zelica pagasa (Druce), Napeogenes tolosa amara Godman and Pteronymia notilla Butler \& Druce. Breeding and oviposition in all of these sympatric species occur regularly at the study site between June and September. Adults of all species are generally active at the same times of day and fly at about the same level (just above the herbaceous layer) in the forest. With the exception of $O$. zelica and N. tolosa the larval food plants of these species have been determined (Young, in prep.) and these are in various genera and species of Solanaceae. But H. nero is the only ithomiine feeding on Cestrum standleyi. Pteronymia notilla feeds on C. megalophyllum Dum. and the other species on various species of Solanum (Young, in prep.). Food plant specialization is high in this ithomiine community.

\section{Life cycle and developmental time}

The stocky egg $(0.75 \mathrm{~mm}$ high $\times 0.70 \mathrm{~mm}$ wide $)$ tapers slightly to the top and is characterized by many longitudinal deep grooves (Fig. 2-A). The central area at the top of the egg is depressed and the egg is uniformly white until hatching.

There are five instars in larval development. All five instars are similar to one another, but the following differences occur. The first 

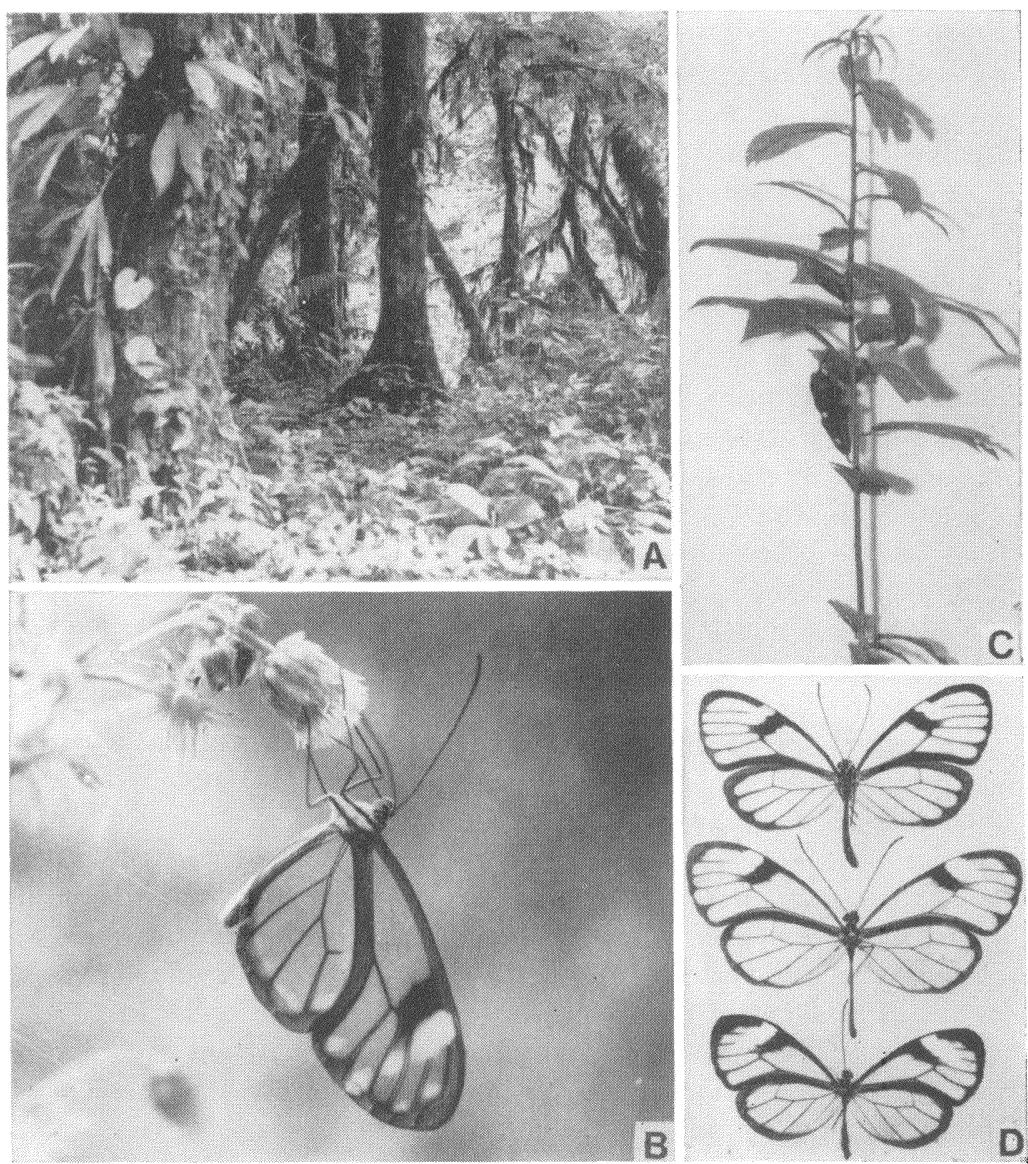

Fig. 1. Ithomiine natural history. (A) habitat at Cuesta Angel where several clear wing ithomiines co-occur; (B) male Hymenitis andromica lyra on Eupatorium sp., a major adult food plant for seventh ithomiines, including $H$. nero; (C) Cestrum standleyi Morton (about $1.0 \mathrm{~m}$ tall), larval food plant of $H$. nero; (D) three similar-appearing clear wing ithomiines co-occurring at Cuesta Angel, from top to bottom: Hymentiis nero, H. andromica lyra, and Pseudoscada utilla pusio. 
instar is uniformly dark green after an initial feeding, although it is yellowish-white immediately after hatching. As it grows, a thin, dorso-lateral line becomes evident on each side of the body and the larva is about $6.5 \mathrm{~mm}$ long by the first molt. The second instar is lighter green and the head is translucent yellowish-green, and bears a small black spot ventro-laterally on each side. A dorso-lateral yellow stripe separates the darker upper portion of the body and the lighter yellow-green ventral portion. There is also a medial dorsal stripe which terminates indistinctly anteriorly on the second segment and posteriorly on the ninth segment. The third instar (Fig. 2-6) is very similar to the previous one. By the third molt, the larva is about $12 \mathrm{~mm}$ long. The fourth instar (Fig. 2-D) is more decorative than previous instars. The head remains yellowish-green but now has acquired a second pair of black spots immediately above the first pair. The second pair of spots are considerably larger and triangular in shape. The dorsal region of the body is a light, chalky green and is bounded laterally by a prominent double stripe (Fig. 2-D). The upper component of the double stripe is very dark green and the lower component is white, but the latter fades into yellow in the posterior one-third of each body segment. Each spiracle is bordered with a thin yellow line. This color pattern is retained in the fifth instar. The larva measures about 2 $\mathrm{I} \mathrm{mm}$ in length by $3 \mathrm{~mm}$ in width at the time of pupation.

The pupa is about $10 \mathrm{~mm}$ in length and $9 \mathrm{~mm}$ wide dorso-ventrally through the thoracic region. The cremaster is light red and the spiracles are bordered in light yellow. A few hours after formation, the pupa becomes silvery in appearance with the wing pads being entirely silver in color and anterior-ventral aspects as well (Fig. 2-E, F). The dorsal region of the abdomen acquires two powder light blue stripes which taper towards the cremaster. The leading edge of each wing pad is dark red. Pupation in the field does not occur on the host plant.

The adult female is figured in Fig. 2-G, including both dorsal and ventral aspects. The average wingspan for females in this population is $47.6 \pm 0.4 \mathrm{~mm}(\mathrm{~N}=\mathrm{I} 6)$ and for males, $45 \pm 1 . \mathrm{I}(\mathrm{N}=$ 20). Sexual dimorphism in coloration is very weak, and both sexes have the same distribution of color. But coloration is more extensive in the female. The basic color of the non-transparent dorsal wing surfaces is slate gray with white spots; ventrally gray is replaced by dull red with the exception of the trailing edges of forewings (these being gray). A description of the adult is given by R. Haensch; in Seitz (1924), and in Fox (1968). 

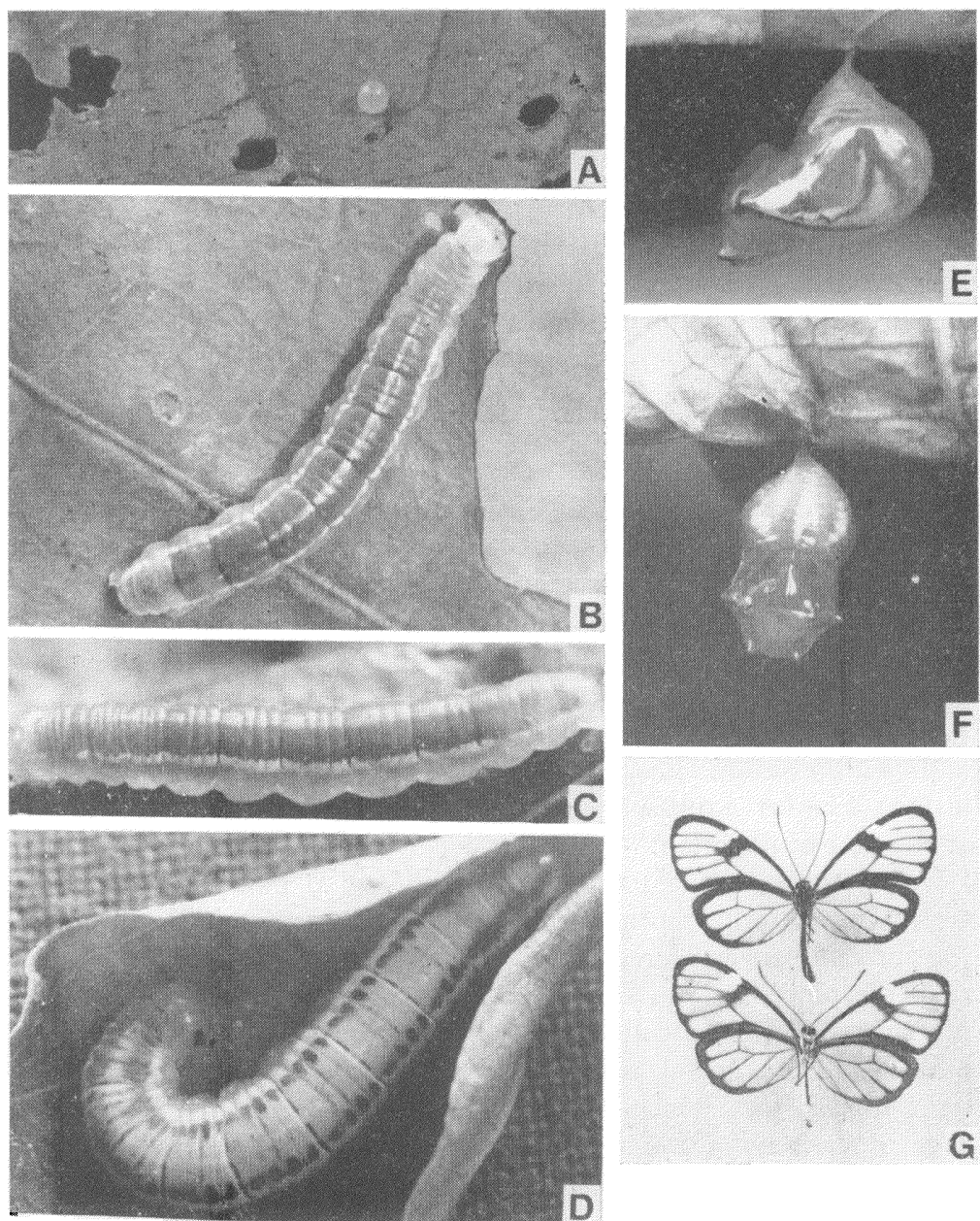

G

Fig. 2. Life stages of Hymenitis nero. (A) egg; (B-C) third instar; (D) fourth instar; (E-F) pupa; (G) adult female. 
The egg-adult developmental time is summarized in Table I and no difference was observed between sexes.

\section{Larval behavior}

All instars remain on the dorsal surfaces of leaves throughout their development in the field; both feeding and resting activities are confined to dorsal leaf surfaces. First and second instars build thin silken mats for resting behavior; these mats are usually located near the center of the leaf. Larvae are never gregarious and this is correlated with oviposition behavior (see below); larval densities seldom rise above 3 per individual host plant. Only one larva was found per leaf in sample of 33 plants bearing larvae. First to third instars appear very cryptically colored but the fourth to fifth instars are more conspicuous, owing to the very light green dorsal body surface accompanied by the lateral double striping pattern. But these larvae build a "nest" by curling in the proximal edges of large leaves of the host plant, and anchoring these in place with a few silken strands (Fig. 2-D). The larva builds a thick silken mat inside this enclosure, presumably as a resting site. The nest is seldom completely closed over but the curling in appears sufficient enough to render the larva inconspicuous in shadows created by the leaf edges. The third instar exhibits a form of nest-cleaning behavior in which pieces of accumulated excrement are taken up in the mandibles and tossed outside the nest. Foraging usually occurs on the same leaf as the nest, and when a leaf becomes about half eaten away, the larva abandons the next for another leaf and builds a new nest. As in earlier instars, the third instar always returns to the silken mat between foraging episodes. First and second instars are strictly nocturnal feeders, while the third instar feeds erratically day and night.

First and second instars have the usual capacity to suspend themselves from a leaf at the approach of a potential predator (such as an ant). Curiously, this behavior cannot be elicited by solely mechanical means. Later instars do not exhibit this behavior.

\section{Adult behavior}

Adult population densities at the study site are exceedingly low on a daily basis. It is therefore difficult to obtain quantitative data on patterns of adult activity. But oviposition sequences were observed on a total of 18 days at the study site, and presumably these involved several different females, although this cannot be confirmed until data are available on home range movements of adults. For example, a roost of several adults of clear wing ithomiines was found in lowland wet forest (Finca la Selva) at 4:30 PM on August 12, 
I969 (A. M. Y., unpubl. field notes). It is therefore possible that local movements of adults of at least some ithomiines are in the form of consistent day-to-day patterns (home ranges).

Table 1. The developmental time ${ }^{a}$ of Hymenitis nero (Ithomiinae) on its host plant, Cestrum standleyi (Solanaceae).

Instars $\mathbf{s}^{\mathrm{b}}$

\begin{tabular}{lcccccc} 
Statistic & Egg & $1-2$ & 3 & $4-5$ & Pupa $\begin{array}{r}\text { Total Time } \\
\text { Egg-Adult }\end{array}$ \\
\hline $\begin{array}{l}\text { Mean Duration } \\
\text { (Days) }\end{array}$ & 4 & 3 & 5 & 7 & 11 & 30 \\
S. E. & 0.3 & 0.7 & 0.4 & 0.4 & 1.2 & \\
No. & 20 & 18 & 18 & 18 & 18 & \\
Died & 0 & 2 & 0 & 0 & 0
\end{tabular}

ameasured in the laboratory

bdata are lumped for instars since head capsules were not collected for each instar.

Oviposition occurs on plants of a wide height range, this being 0.3 to $\mathrm{I} . \mathrm{O} \mathrm{m}$ at the study site. Eggs are always laid singly with only one egg per leaf and usually only one or two eggs per plant. The egg is always laid on the dorsal leaf surface, and usually in the central region near the midrib. These observations were gathered from a total of 53 oviposition sequences observed at the study site during July and August. There is no apparent selection for young leaves during egg-laying, and most eggs are, in fact, laid on older leaves. Height distribution of eggs on individual plants of similar size is very variable.

Female vagility may be high in this species since it is observed that individual females pass through the study site pausing briefly for oviposition. However, no marking studies have been done to assess the extent of vagility in either sex. As mentioned earlier, however, the larval food plant has a highly dispersed local distribution and does not occur as extensive homogeneous patches. Such food plant dispersion would favor high vagility in non-colonial butterflies.

\section{Discussion}

Various ecological traits of butterflies, including larval defensive behavior, palatability, mimicry, breadth of food plant acceptance, and oviposition have been recently discussed in terms of community structure (e.g., Brower and Brower, 1964; Ehrlich and Raven, 1965; 
Eisner, 1970; Young, 1972). Several of these factors are discussed below for $H$. nero, and in relation to other ithomiine genera, from three major considerations: (I) palatability and mimicry, (2) strategies of oviposition, and (3) defensive behavior of larvae.

\section{Palatability and Mimicry}

The Ithomiinae have long been known to be generally unpalatable butterflies since the larvae of most species feed on various Solanaceae, and this prediction has been verified for adults of selected species (Brower and Brower, 1964). The larvae of H. nero feed on Cestrum in the Solanaceae and are therefore presumably unpalatable. As to be discussed below, this unpalatability may not be characteristic of all life stages. Together, adults of at least three species, $H$. nero, $H$. andromica, and Pseudoscada utilla appear very similar, in terms of size, coloration, and wing transparency (Fig. I-D). The local sympatry of these species at Cuesta Angel lends further credence to the prediction that they form a Müllerian mimicry complex. But until the relative palatabilities of adults and larvae of all three species are determined, along with estimations of relative abundances of adults in local habitats, the hypothesis of Müllerian mimicry cannot be tested. The very existence of the rather cryptic clear wing phenotype in many ithomiine species throughout Central and South America suggests that while these species derive protection from their transparency, they undoubtedly derive some advantage from being mimetic. This problem clearly needs more quantitative and chemical study for both larvae and adults.

\section{Strategies of Oviposition}

The single oviposition pattern of $H$. nero is characteristic of many other ithomiines, in addition to being the general rule in butterflies as a group (Labine, 1968). Yet it is clear that other patterns of oviposition exist in other ithomiine genera. In another report (Young, in prep.), it is shown that the ithomiine Godyris zavaleta lays loose clusters of eggs on the ventral leaf surfaces of Solanum hispidum. As a result of this oviposition pattern, it is not uncommon to find several larvae together on a single leaf. But these larvae show no coordinated gregarious behavior and individuals seldom have physical contact with one another. Yet in another genus, Mechanitis, species such as $M$. isthmia exhibit tight clustering of eggs in well-defined rows on ventral surfaces of leaves of solanaceous food plants in both Costa Rica and El Salvador (Young, in prep.). Furthermore, larval gregariousness is very apparent, with both resting and feeding activities being highly synchronized and coordinated among the individ- 
uals in a group derived from a single cluster of eggs. From these preliminary observations, it seems that different genera of ithomiines possess very different strategies of oviposition and subsequent larval behavior. With further field studies on these and other Costa Rican species within selected genera, it will be possible to examine these adaptations in terms of phylogenetic affinities within the Ithomiinae. Other field studies will emphasize the correlation of ecological properties of habitat and how these influence the type of oviposition and clustering of larvae.

\section{Defensive Behavior of Larvae}

Earlier larval instars of $H$. nero are relatively more cryptic in appearance than the fifth instar and do not build solitary nests. Final instar larvae build solitary nests (Fig. 2-D) and are more brightly colored than earlier instars. These behavioral and morphological differences among instars suggest differences in palatability of larvae as a function of their age. The nest-building behavior of solitary final instar larvae may be an adaptation against invertebrate (ants, predatory hemipterans, spiders, whip scorpions, etc.) and small vertebrate (lizards and frogs) predators that forage in understory herbage. The increased conspicuousness in coloration of the final instar suggests increased unpalatability while the nesting behavior indicates reduced unpalatability. This resulting level of intermediate unpalatability may be carried over from the final instar to the adult, as indicated in the latter by the crypsis of wing transparency.

It is likely that species of Hymenitis such as nero are generally only intermediate in unpalatability as compared to various orangewing genera such as Mechanitis and Godyris which are probably very unpalatable. The more pronounced unpalatability of these latter genera is suggested by (I) brighter coloration of larvae and adults, (2) various types of cluster oviposition patterns, and (3) various levels of larval gregariousness, ranging from loose (i.e., Godyris) to highly coordinated (i.e., Mechanitis) behavior among individuals. But since it is known that many unpalatable tropical butterflies, most notably in the Heliconiinae, have single oviposition and solitary larvae (Alexander, I96I), it is essential to determine the relative palatability of species among these ithomiine genera before making such correlations. Many other selection pressures not related directly to the development and expression of unpalatability may account for the evolution of cluster oviposition and larval gregariousness.

\section{Summary}

( I) The life cycle, developmental time, and larval host plant 
record are summarized for the butterfly, Hymenitis nero (Hewitson) (Ithomiinae), in montane wet forest on the Caribbean slopes of the central Cordillera in Costa Rica.

(2) It was found that the larval food plant is Cestrum standleyi Morton in the Solanaceae.

(3) The butterfly co-occurs with several other ithomiines which breed regularly in the same plant community, but each of these species had a different host plant. At least two of these other species have the same color pattern as H. nero, and as such may be Müllerian mimics.

(4) But the unpalatability of $H$. nero may be questionable since the larvae exhibit both cryptic coloration and behavior (nocturnal feeding, nest building, etc.). Unpalatability is suggested mainly by the host plant being the Solanaceae. Experimental feeding studies are needed to verify unpalatability.

(5) Preliminary studies of life cycle and natural history in other selected ithomiine species in different genera suggest that strategy of reproduction and larval defense may vary consistently within the phylogeny of the group.

\section{ACKNOWLEDGEMENTS}

This is a contribution from a College Science Improvement Grant (COSIP; Gy-47II) awarded to Lawrence University. Laboratory facility and logistic support were provided by the Costa Rican Field Studies program of the Associated Colleges of the Midwest. Patrick Eagan (Lawrence) assisted in all field and laboratory studies in 197 I while Roger Kimber and John Thomason assisted in 1972. Dieter C. Wasshausen (Smithsonian Institution) identified the larval food plant. Dr. Keith S. Brown (Rio de Janeiro) identified the ithomiines discussed, and criticized an earlier version of the paper.

AleXander, A. J.

\section{Literature Cited}

1961. A study of the biology and behavior of the caterpillars, pupae, and emerging butterflies of the subfamily Heliconiinae in Trinidad, West Indies. Part I. Some aspects of larval behavior. Zoologica 46: 1-24.

Brower, L. P., AND J. V. Z. Brower

1964. Birds, butterflies, and plant poisons: a study in ecological chemistry. Zoologica 49 : 137-159.

Ehrlich, P. R., and P. H. Raven

1965. Butterflies and plants: a study in coevolution. Evolution 18: 586-608. 
EISNER, T.

1970. Chemical defense against predation in arthropods. pp. 157-217, In: E. Sondheimer and J. B. Simeone (eds.). Chemical Ecology, New York: Academic Press, 336 pp.

Fox, R. M.

1956. A monograph of the Ithomiidae (Lepidoptera). Part I. Bull. Amer. Mus. Nat. Hist. 111: 1-76.

1968. Ithomiidae of Central America (Lepidoptera: Nymphaloidea), Trans. Amer. Ent. Soc. 94: 155-208.

Seitz, A.

1924. Macrolepidoptera of the world. Vol. 5. The American Rhopalocera. A. Kernan Verlag, Stuttgart.

Young, A. M.

1972. Breeding success and survivorship in some tropical butterflies. Oikos 23 (in press). 

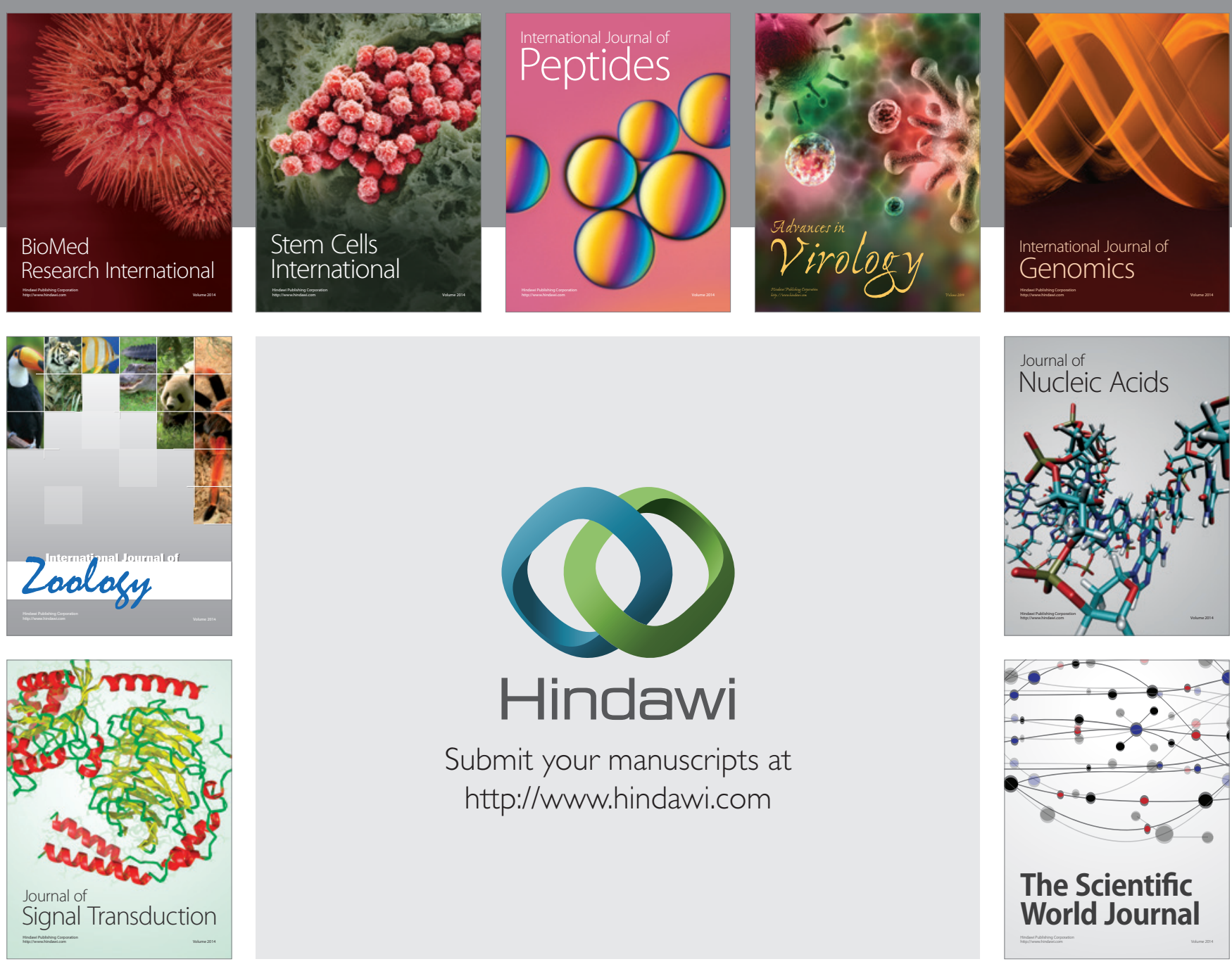

Submit your manuscripts at

http://www.hindawi.com
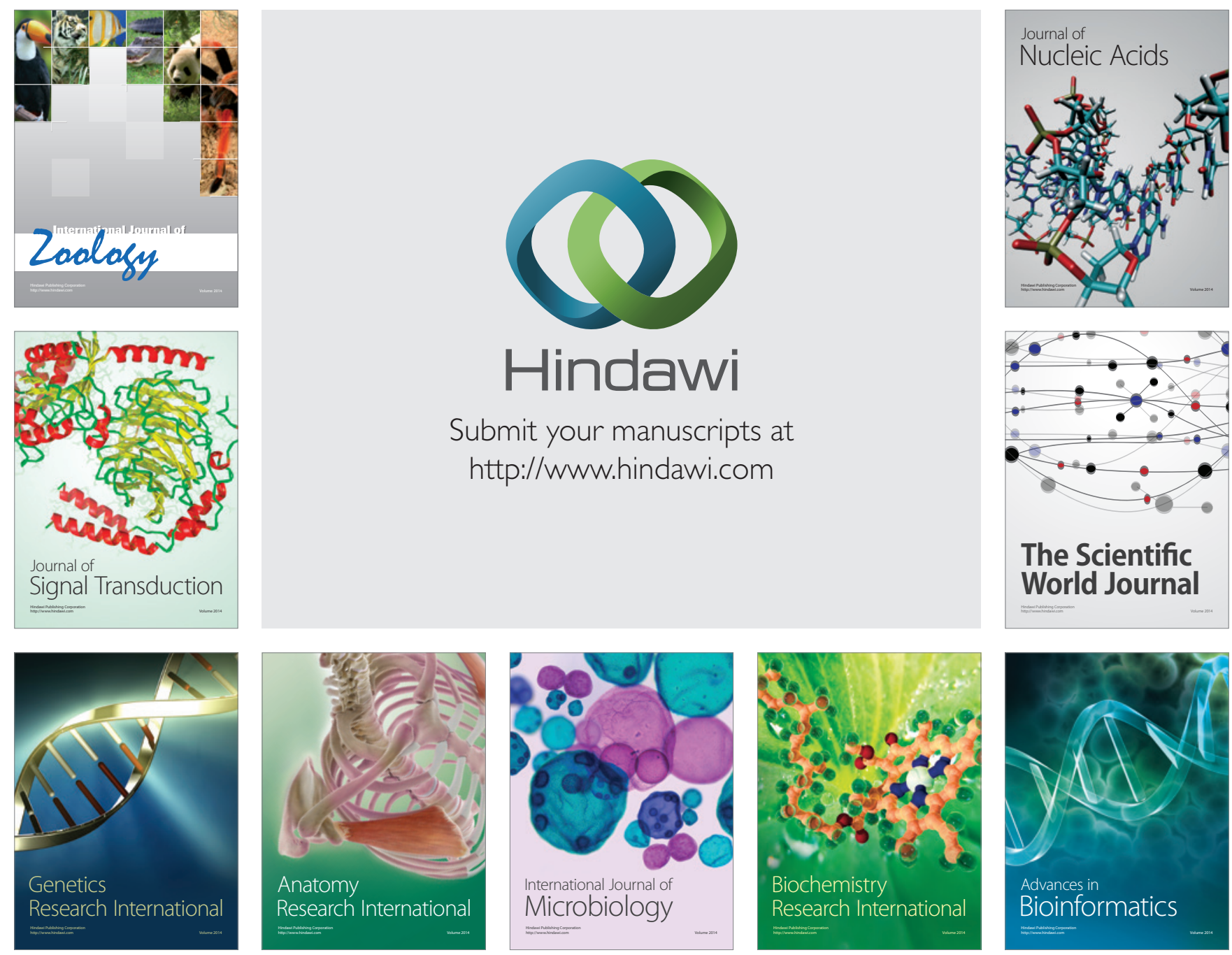

The Scientific World Journal
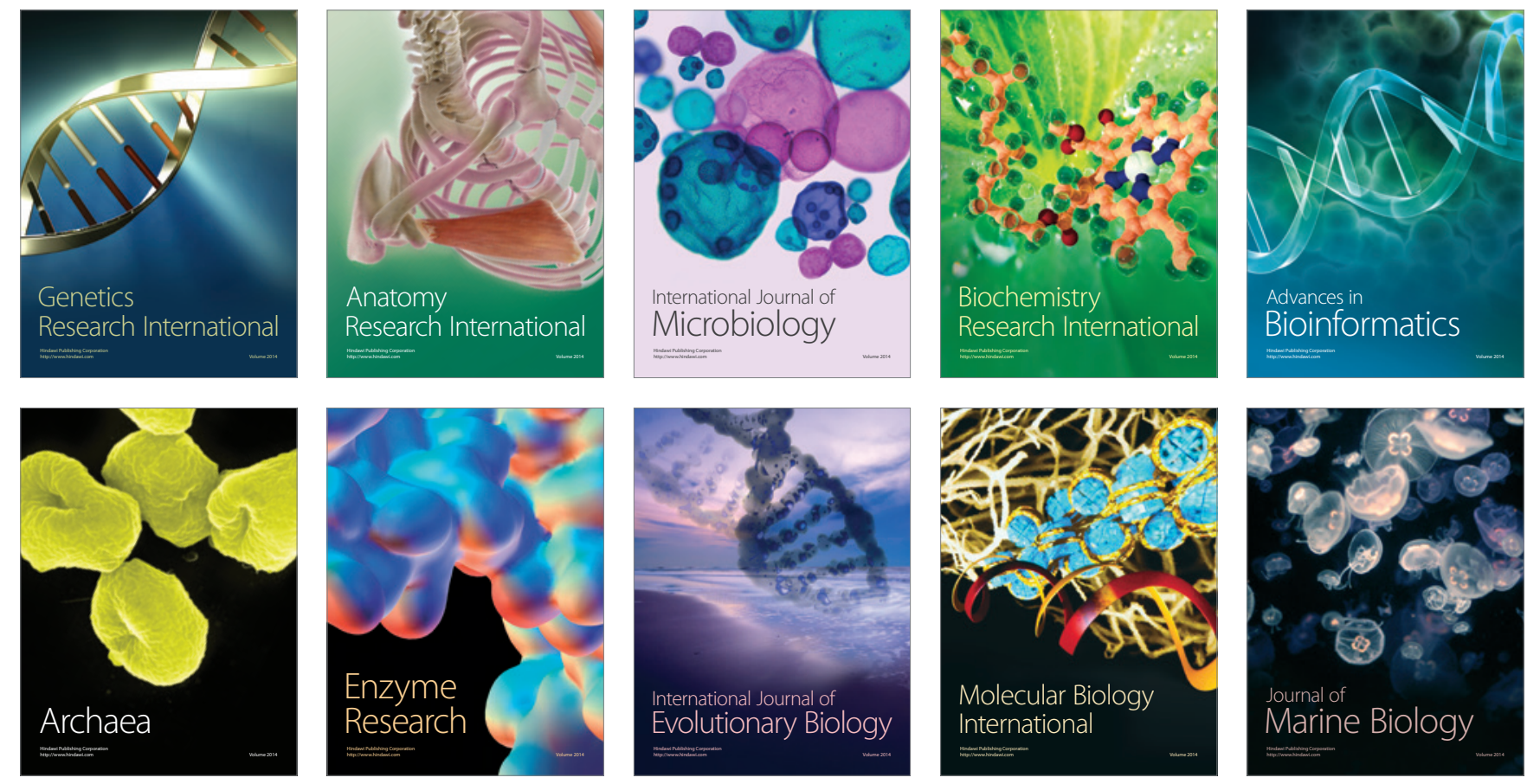